\title{
A Retrospective Analysis of the Capacity Built through a Community-Based Participatory Research Project Addressing Diabetes and Obesity in South and East Los Angeles
}

\author{
Kathryn Hillstrom*, Valerie Ruelas, Anne Peters, Turusew Gedebu-Wilson, Ellen Iverson \\ California State University, Los Angeles, USA \\ Email: kkgraves@calstatela.edu
}

Received 27 April 2014; revised 31 May 2014; accepted 8 June 2014

Copyright (C) 2014 by authors and Scientific Research Publishing Inc.

This work is licensed under the Creative Commons Attribution International License (CC BY). http://creativecommons.org/licenses/by/4.0/

c) (i) Open Access

\section{Abstract}

Chronic diseases, such as diabetes and obesity, are more prevalent in low-income and minority communities. One promising method to understand and address these chronic conditions is through Community Based Participatory Research (CBPR). CBPR engages and empowers community members to identify risk factors and work toward solutions as equal partners with researchers. One positive and lasting outcome may be an increase in the community capacity which includes individual and community leadership development, policy making, creating connections and utilizing existing community resources. Evaluating community capacity created as a result of a CBPR project is one way to measure its effectiveness. This paper is a retrospective analysis of the capacity built during a CBPR study of diabetes and obesity in East and South Los Angeles which are two low-income and minority neighborhoods. Four people, who were heavily involved in the project, completed a retrospective analysis of the capacity built utilizing a validated instrument. There was consensus about the capacity built, which included: excellent participation by community members, inclusion of members' ideas to leverage additional funding, and pride of community members in their participation in the project. One area that could have been strengthened was increased access for leadership and research experience among community members, especially since the project ended prematurely. There were differences among the two community groups with East Los Angeles members focusing more on tangible interventions and grant writing, while South Los Angeles members had a greater policy focus. Communities and researchers who are embarking on a CBPR project can learn from those who have implemented the strategy. Measuring capacity built during and after the project, can be one way to understanding the contribu-

*Corresponding author.

How to cite this paper: Hillstrom, K., Ruelas, V., Peters, A., Gedebu-Wilson, T. and Iverson, E. (2014) A Retrospective Analysis of the Capacity Built through a Community-Based Participatory Research Project Addressing Diabetes and Obesity in South and East Los Angeles. Health, 6, 1429-1435. http://dx.doi.org/10.4236/health.2014.612175 
tions of a project in a community. CBPR is an empowering research methodology which, done correctly, can build community capacity and have long-term impacts on individuals and communities.

\title{
Keywords
}

\author{
Community-Based Participatory Research, Diabetes, Minority Health, Health Research
}

\section{Introduction}

The obesity epidemic is widely discussed in research. Currently, two-thirds of American adults are either overweight or obese [1], and a third of American children are overweight or obese [2]. The consequences of being overweight and obese are a higher likelihood of developing myriad health issues, including diabetes. Diabetes rates are at an all-time high with national averages of diagnosed and undiagnosed rates estimated at 9.3\% [3]. Diabetes is much more prevalent among minority populations, with twice as many non-Hispanic blacks and Mexican Americans being diagnosed compared to non-Hispanic whites [4]. One promising approach to study and address obesity and diabetes is by using community-based participatory research (CBPR) to engage communities most affected by the epidemic to understand factors affecting risk and identifying solutions [5]. CBPR is described as "a collaborative approach to research that equitably involves, for example, community members, organizational representatives, and researchers in all aspects of the research process" [6]. Researchers and community members work together as equals from the inception of research design, through development and implementation, to the dissemination step of the process. CBPR has also been found to lead to increased participation, lower drop-outs, and increased capacity but for the long-term, little research exists about direct or indirect capacity built [7]. CBPR can be an effective means of empowering stakeholders to address issues affecting the health and well-being of their communities, but there is now a greater understanding of the many challenges of applying CBPR in practice [8]. It is imperative to continue to evaluate the CBPR process so others planning to utilize it as a research methodology or fund CBPR studies can understand and anticipate its strengths and limitations. An important outcome that has been under-studied is the effect of CBPR on building long-term, sustained community capacity to address issues affecting their local environments. Community capacity was defined in 1995 by a working group of the Center for Disease Control as "participation and leadership, skills, resources, social and inter-organizational networks, sense of community, understanding of community history, community power, community values, and critical reflection” [9]. One tool to measure capacity building was developed based on: "1) leadership that provided a driving force for implementation, 2) policy making that ensured diffusion and sustainability, and 3) use of local community resources and infrastructure” [10]. From there, a validated and reliable instrument was developed [11] and has been utilized by researchers to assess capacity built in a community context. For example, The Alberta Healthy Heart Project, which was a population health intervention to address obesity and chronic disease prevention, utilized the capacity-building tool and found it to be an effective way to analyze their CBPR project during and after implementation and provided evidence of the effectiveness of a project [12]. This paper seeks to trace the capacity built during the initial two-year planning phase of the Keck Diabetes Initiative, which began in 2004. The WM Keck Foundation funded a multi-disciplinary research team from the University of Southern California and Children's Hospital Los Angeles to launch the Keck Diabetes Prevention Initiative (KDPI)—a community-research partnership targeting two communities in Los Angeles who are disproportionately affected by obesity and diabetes (see Table 1). Because both communities are so distinct, effort will be made to point out why certain capacity building may have been achieved and sustained in one area but not in another. There will also be discussion about the resources which remain in the communities ten years later as a result of the initial project. The hope is that researchers wanting to implement CBPR will draw upon the successes of this program but also be aware of the challenges that were encountered.

\section{Methods}

The first two-years of the KDPI project were dedicated to relationship-building and data collection through a 
Table 1. Community profiles for East and South Los Angeles.

\begin{tabular}{|c|c|c|}
\hline & 90022-East Los Angeles & 90059-South Los Angeles \\
\hline Population $^{*}$ & 68,688 people & 38,123 people \\
\hline Ethnicity $^{*}$ & $\begin{array}{l}\text { Latino-96\%; majority are } \\
\text { of Mexican descent }\end{array}$ & $\begin{array}{c}\text { African American-46\% } \\
\text { Latino- } 53 \%\end{array}$ \\
\hline $\begin{array}{l}\text { Families living } \\
\text { below poverty line* }\end{array}$ & $\begin{array}{l}25 \% \text { (compared to } 9 \% \text { for } \\
\text { US) }\end{array}$ & $39 \%$ (compared to $9 \%$ for US) \\
\hline $\begin{array}{l}\text { Median household } \\
\text { income* }\end{array}$ & $\$ 27,471$ & $\$ 22,151$ \\
\hline Education $^{*}$ & $\begin{array}{l}36 \% \text { of those over } 25 \mathrm{yr} \\
\text { old have a high school education }\end{array}$ & $\begin{array}{l}44 \% \text { of those over } 25 \text { yr old } \\
\text { have a high school education }\end{array}$ \\
\hline Diagnosed diabetes $^{+}$ & $11 \%$ & $12.3 \%$ \\
\hline
\end{tabular}

"US Census (2000). Retrieved on January 9, 2012 from http://www.census.gov/; ${ }^{+}$LA Department of Public Health, Office of Health Assessment and Epidemiology; Key Indicators of Public Health by SPA; June 2009.

http://publichealth.lacounty.gov/wwwfiles/ph/hae/ha/KIR_2009_FINALr1.pdf

multi-layered, mixed method design. A team of researchers and project managers was assembled. Information collected during the first two years included: 110 semi-structured interviews with community members and key informants; inventories and surveys of 100 supermarkets, grocery stores, and corner markets in both zip codes; geospatial mapping of healthy food venues in relation to schools in the neighborhoods [13]; systematic surveys of parks to assess safety and usage; and a random digit dialing phone survey of 250 residents in each community assessing food consumption and behavior, physical activity and health status. Simultaneously, project managers assembled a Community Advisory Board (CAB) of stakeholders in each neighborhood. The first two years were dedicated to begin to understand the communities and to developing a strong connection with each community through the CABs. The plan was that following the first planning phase, an intervention phase lasting eight years would begin. Funding ended unexpectedly after the initial two years. This evaluation focuses on local infrastructure and resources building for the prevention of diabetes and obesity that occurred as a result of the community participatory process that took place in the initial two years of the project. For this paper, a case study method, suggested by Israel et al. (2005), has been utilized to evaluate capacity building that occurred during this time period. The data collection technique for this evaluation was qualitative and utilized a variety of sources. The first was through an analysis of the project by the four of the six most involved people in the project: the two Registered Dietitians, the director of the project, and the director of the research team. As a retrospective analysis, an assessment and documentation was completed to determine what still exists in the two communities including ongoing community interventions and connections. A large part of the present discussion will be those factors that assisted with the project, those which hindered it, and the lessons learned through the experience. A capacity-building survey created by Maclellan-Wright (2007) was administered to the four key project members. The survey contains nine features with 26 individual items to measure capacity building. The project team members were asked to reflect on their perceptions and experiences related to each feature and provide supportive commentary. No attempt was made to arrive at a consensus. What is valuable is the diversity of opinions about each item. Findings from this process are organized into the nine capacity building features with definitions provided for each.

\section{Results}

\subsection{Participation}

"Participation is the active involvement of people in improving their own and their community's health and well-being” [11]. For the Community Advisory Boards in each area, members who lived or worked in the priority zip codes and who had an interest in obesity and/or diabetes were invited to attend. Many of the CAB members were recruited as a result of participating in the interviews of key stakeholders by the research team. After the interview, they were asked if they wanted to participate as a CAB member, and they, in turn, invited other people. CAB meetings were held monthly. In both communities, over 30 members attended the first meeting, but after a couple months, the number declined to about 12 - 15 steady participants. Initially, in East LA, participants were confused about their role and believed CAB meetings were diabetes education classes rather than a 
research planning group in which their input and participation was needed and expected. In South LA, the invited members knew they were participating in research and the first meeting was dedicated to trust building and discussing their conflicting feelings about academia and past negative experiences with researchers. Both CAB membership included members representing a variety of individual and organizational perspectives and backgrounds. Membership included representatives from the local chapter of the American Diabetes Association, intake counselors from the local Senior Centers, diabetes educators from a community clinic, residents living with diabetes, community activists who were heavily involved in issues such as improving the parks and safety in the neighborhood, and nutrition students from the local universities. In East LA, the meetings were held across the street from the County Supervisor's office and the California State Senator's office, which facilitated attendance of their health deputies and other representatives. Attendees were encouraged to bring their spouses and family members and many did. The meetings were held in the evenings and in East LA, conducted in both English and Spanish. As an incentive and to demonstrate the availability of healthy options in East LA, a healthy dinner was provided from local restaurants. In South LA, due to the scarcity of healthy restaurants, the meetings were held each month at the Watts Café. Childcare was not offered nor was it mentioned by attendees as an obstacle. Initially, the goal was to move around the community and have meetings at different locations, but the attendees actually preferred to have the meetings in one location to minimize confusion and parking difficulties. Therefore, the meetings were held each month in East LA, at the local clinic and in South LA, at the Watts Café. The East LA CAB participation evolved beyond meeting attendance as many played active roles in realizing and delivering interventions ideas that the CAB had generated. For example, East LA CAB members played an active role designing and implementing an Obesity and Diabetes Town Hall meeting for local residents. CAB members were actively engaged in planning, marketing and presenting educational materials and resources. In addition, a few members were hired to help with an intervention in local supermarkets to place healthy recipes and posters encouraging increased consumption of fruits and vegetables. In contrast, South LA CAB participation was focused on advocating for policy changes. For example, CAB members attended the LA County Board of Supervisor's meetings to voice their support of the ban on soda in the Los Angeles Unified School District.

\subsection{Leadership}

"Leadership includes developing and nurturing both formal and informal local leaders during a project" [11]. While no formal leadership development or skill-building took place, leadership emerged as members took on leadership roles in generating ideas and implementing community-focused interventions. These roles were not defined at the onset and most initially played a more participatory role rather than guiding role during the CAB meetings. However, the interests of the individual $C A B$ members guided the discussions each week and elements of the Town Hall meetings were a result of the interests of the group. For example, in East LA, the members were interested in a supermarket intervention and in South LA, the discussions were more policy-oriented. Since many attendees had diabetes or had family members with diabetes, they requested diabetes education. Therefore, the dietitians assigned to each area included a short lesson on diabetes management at every meeting.

\subsection{Community Structures}

"Community structures refers to smaller and less formal community groups and committees that foster belonging and give the community a chance to express views and exchange information" [11]. The project coordinators were able to effectively link with pre-existing community structures such as churches and informal community groups. Many were identified through interviews with key informants and community members and they welcomed our information. Consequently, many of the leaders of these community structures and organizations began to attend monthly $\mathrm{CAB}$ meetings.

\subsection{External Supports}

"External supports (funding bodies) such as government agencies, foundations, and regional health authorities can link communities and external resources" [11]. The initial funding from the WM Keck Foundation supported planning and community capacity building efforts, but did not support interventions that were proposed and developed by virtue of this process. When the planning funding ended, members of the research team attended county-wide health meetings to learn of resources and grants that were available for the communities to 
support interventions, and $\mathrm{CAB}$ members provided support in developing proposals. In East LA, modest funding was obtained through the combined efforts of the team and CAB to support supermarket tours and post information about fruits and vegetables in the grocery stores. In South and East LA, the CABs and the research team collaborated with other community organizations to bring farmer's markets to both communities.

\subsection{Asking Why}

"Asking why refers to a community process that uncovers the root causes of community health issues and promotes solutions" [11]. A primary focus of the KDPI was to partner with community stakeholders to explore and identify why diabetes and obesity affect more people in these two neighborhoods than in other parts of Los Angeles. One method to further the knowledge was through in-depth, qualitative interviews with key informants and community members. Utilizing the Socio Ecological Model as a springboard for CAB discussions was enormously effective to establish conversation about factors influencing obesity and diabetes and for generating ideas about possible solutions [14]. The model recognizes the layered influences of individual, familial, cultural, and structural factors on community obesity and diabetes. The CAB modified the model and it resonated for most $\mathrm{CAB}$ members, making it easier to disentangle and identify multiple contributors to the problem and focus on interventions targeting specific contributors. Both communities were also in favor of starting farmer's markets, and currently, they are going strong in both neighborhoods [15].

\subsection{Obtaining Resources}

"Obtaining resources means finding time, money (other than from funding bodies), leadership, volunteers, information and facilities both from inside and outside the community" [11]. Both communities have rich cultural resources. Both have a long history of overcoming challenges and ties to the areas' heritages are strong. One advantage in East LA is that the meetings were consistently held in the local county clinic, which provides free and reduced-cost care to residents. The research team had offices in the same building, which made it convenient and increased project team visibility. One of the team leaders is an endocrinologist with a long history of working in East LA. She is an advocate for health, especially among underserved populations. To this day, she continues her work in the same clinic and has been instrumental in receiving other grants to continue the work in these neighborhoods. External resources were also adequate, including educational materials, and access to prior and current research. Obtaining resources in South Los Angeles was far more challenging for the project team. The project offices were located 14 miles from South LA. Consequently, the research team did not have the day-to-day visibility the East LA community enjoyed. Additionally, this distance created challenges for establishing a stable meeting place and inhibited informal meetings and gatherings with community partners, which is essential to deepening relationships and trust. This should be a consideration for future researchers - rent or find local space in the community.

\subsection{Skills, Knowledge, and Learning}

"Skills, knowledge, and learning are qualities in the project team, the target population, and the community that the project team uses and develops" [11]. The project team, comprised of the two project coordinators and two Registered Dietitians, brought critical skills, knowledge and experience that supported community capacity building. All four were familiar with the culture of the neighborhoods the initiative targeted; two were bilingual, and two were Registered Dietitians with over a decade of experience each working in weight management and with people with diabetes. The project administrator and research director had experience with implementing grants, collecting qualitative data, and recruiting and running CABs. The project administrator was actively engaged in multiple local coalitions focusing on obesity and diabetes prevention which facilitated helpful connections with other agencies with a similar focus on obesity prevention. The CAB members all had a vested interest in learning about diabetes prevention and treatment as many were either living with diabetes or had family members with diabetes. The monthly meetings began with a time for the members to name aloud people living with diabetes and time was taken to reflect on their daily struggles. At the end of the first two years of the grant, East LA CAB members organized a Town Hall meeting open to all community residents to report barriers and suggest strategies for healthy eating and physical activity. CAB members helped in all aspects of the Town Hall including food selection, who to invite, content of the meeting, and ensuring the meeting ran smoothly. For the roughly 200 attendees in East LA, CAB members proudly showcased their involvement in the project. In South 
LA, no culminating Town Hall occurred.

\subsection{Linking with Others}

"Linking with others refers to linking your project with individuals and organizations" [11]. Endorsement by local leaders and agencies was critical to the KDPI's success in establishing credibility and trust of community stakeholders. The research team established connections and ongoing communication with local county supervisors, school principals and administrators, law enforcement personnel, clinics providing diabetes care and education, churches, youth organizations, e.g., Boys and Girls Clubs, and many other non-governmental agencies. The project administrator also advocated for changes on a county-wide level through her involvement in cross-county coalitions and policy groups. During monthly CAB meetings, different agencies were invited to share what they were doing in the community to help agencies become aware of one another and for community members to learn about resources. One finding was that services were often available but community members were unaware of them, and at other times, agencies had a duplication of services and the agencies were unaware of the redundancy. Because funding ended before the implementation stage, it is impossible to know the strength and breadth of the linkages which resulted.

\subsection{Sense of Community}

"Sense of community, within the context of the project, is fostered through building trust with others" [11]. East and South Los Angeles have always had a strong sense of community. Both areas are well known for their activism, their rich cultural history and traditions, and for their sense of community. This was evidenced during the qualitative interviews and when interacting with different community members and agencies. In the past, both communities have a rich history of mobilizing in support of civil rights and against social injustice and inequity; improved public health and greater emphasis on prevention resonated with both communities. At the inception of this project, many of the community members and agencies had experience with diabetes which facilitated obtaining their support for the project. On the other hand, for many people, their concerns were focused more around meeting their daily needs, and so finding people who had time and energy for the project was at times challenging. For the 15 or so consistent members of both CABs, a special bond was formed. They enjoyed coming to the meetings, interacting with other members, and felt that their involvement was important. Membership in the CAB was a source of pride for them. When the project ended unexpectedly, it was also difficult for them to understand and accept. Fortunately, some of the work continued through the grant-writing efforts of the different team members in East LA but not in South LA.

\section{Discussion}

The Keck Diabetes Prevention Initiative was a ten-year diabetes and obesity prevention study, beginning in 2004. The first two years of the project were dedicated to relationship building, exploratory research, and the formation and maintenance of community partnerships through its two community-advisory boards. This paper provides an analysis of the capacity built in the first two years as a result of the project. The strengths of the project in both communities include: wide participation across a variety of key community stakeholders, educating community members on the socio ecological model and integration of their ideas into future interventions, and the pride of $\mathrm{CAB}$ members in their participation in the project. In addition, funding was leveraged as a result of the project through other grants to provide nutrition education and farmer's markets, which are ongoing. Areas that could have been improved include generating more chances for community members to learn leadership skills and practice them and more involvement with the research components. Finally, when the funding was unexpectedly stopped, those community members who had invested large amounts of time and energy in the project and whose expectations for change had been raised were left leaderless and without an effective voice. A limitation of this case study is that the research tool utilized to generate project team responses was employed after the KDPI ended. Consequently, responses reflect retrospective perspectives, and cannot reflect perspectives as events were occurring.

\section{Conclusion}

Communities and researchers who are embarking on a CBPR project can learn from those who have imple- 
mented the strategy. Utilizing a research tool, such as measuring capacity building during and after the project, is very important for understanding the contributions of a project in a community. In addition, if it is utilized during the implementation of a project, the research team can make changes to improve capacity building. In the project described, providing leadership training for members of the $\mathrm{CAB}$ would have contributed to the project but also provided them with a longer-lasting skill set that they could have used to identify and implement initiatives and policies when the study terminated. CBPR is an empowering research methodology which, done correctly, can build community capacity and have a long-term impact on individuals and communities.

\section{References}

[1] Flegal, K.M., Carroll, M.D., Odgen, C.L. and Curtin, L.R. (2010) Prevalence and Tends in Obesity among US Adults, 1999-2008. JAMA, 303, 235-241. http://dx.doi.org/10.1001/jama.2009.2014

[2] Ogden, C.L., Carroll, M.D., Curtin, L.R., Lamb, M.M. and Flegal, K.M. (2010) Prevalence of High Body Mass Index in US Children and Adolescents, 2007-2008. JAMA, 303, 242-249. http://dx.doi.org/10.1001/jama.2009.2012

[3] Cowie, C.C., Rust, K.F., Byrd-Holt, D.D., Eberhardt, M.S., Flegal, K.M., Engelgau, M.M., Saydah, S.H., Williams, D.E., Geiss, L.S. and Gregg, E.W. (2006) Prevalence of Diabetes and Impaired Fasting Glucose in Adults in the US Population: National Health and Nutrition Examination Survey 1999-2002. Diabetes Care, 29, 1263-1268. http://dx.doi.org/10.2337/dc06-0062

[4] Cowie, C., Rust, K.F., Ford, S.F., Eberhardt, M.S., Byrd-Holt, D.D., Li, C.Y., Williams, D.E., Gregg, E.W., Brainbridge, K.E., Saydah, S.H. and Geiss, L.S. (2009) Full Accounting of Diabetes and Pre-Diabetes in the US Population in 1988-1994 and 2005-2006. Diabetes Care, 32, 287-294. http://dx.doi.org/10.2337/dc08-1296

[5] Sloan, D.C., Diamant, A.L., LaVonna, B.L., Yancy, A.K., Flynn, G., Nascimeneto, L.M., McCarthy, W.J., Guinyard, J.J. and Cousineau, M.R. (2003) Improving the Nutritional Resource Community Environment for Healthy Living through Community-Based Participatory Research. Journal of General Internal Medicine, 18, 568-575. http://dx.doi.org/10.1046/j.1525-1497.2003.21022.x

[6] Israel, B.A, Schulz, A.J., Parker, E.A. and Becker, A.B. (1998) Review of Community-Based Research: Assessing Partnership Approaches to Improve Public Health. Annual Review of Public Health, 19, 173-202. http://dx.doi.org/10.1146/annurev.publhealth.19.1.173

[7] Viswanathan, M., Ammerman, A., Eng, E., Garlehner, G., Lohr, K.N., Griffith, D., Rhodes, S., Samuel-Hodge, C., Maty, S., Lux, L., Webb, L., Sutton, S.F., Swinson, T., Jackman, A. and Whitener, L. (2004) Community-Based Participatory Research: Assessing the Evidence. Summary, Evidence Report/Technology Assessment: Number 99. Agency for Healthcare Research and Quality, Rockville. http://www.ahrq.gov/clinic/epcsums/cbprsum.htm

[8] Israel, B.A., Parker, E.A., Rowe, Z., Salvatore, A., Minkler, M., Lopez, J. and Halstead, S. (2005) Community-Based Participatory Research: Lessons Learned from the Centers for Children's Environmental Health and Disease Prevention Research. Environmental Health Perspectives, 113, 1463-1471. http://dx.doi.org/10.1289/ehp.7675

[9] Goodman, R.M., Speers, M.A., McLeroy, K., Fawcett, S., Kegler, M., Parker, E., Smith, S.R., Sterling, T.D. and Wallerstein, N. (1998) Identifying and Defining the Dimensions of Community Capacity to Provide a Basis for Measurement. Health Education \& Behavior, 25, 258-278. http://dx.doi.org/10.1177/109019819802500303

[10] Dressendorfer, R.H., Raine, K., Dyck, R.J., Plotnikoff, R.C., Collins-Nakai, R.L., McLaughlin, W.K. and Ness, K. (2005) A Conceptual Model of Community Capacity Development for Health Promotion in the Alberta Heart Health Project. Health Promotion Practice, 6, 31-36.

[11] Maclellan-Wright, M.D., Anderson, D., Barber, S., Smith, N., Cantin, B., Felix, R. and Raine, K. (2007) The Development of Measures of Community Capacity for Community-Based Funding Programs in Canada. Health Promotion International, 22, 299-306. http://dx.doi.org/10.1093/heapro/dam024

[12] Raine, K.D., Plotnikoff, R., Nykiforuk, C., Deegan, H., Storey, K., Schopflocher, D., Vuegelers, P., Wild, C.T. and Ohinmaa, A. (2010) Reflections on Community-Based Population Health Intervention and Evaluation for Obesity and Chronic Disease Prevention: The Healthy Alberta Communities Project. International Journal of Public Health, 55, 679-686.

[13] Kipke, M.D., Iverson, E., Moore, D., Booker, C., Ruelas, V., Peters, A.L. and Kaufman, F. (2006) Food and Park Environments: Neighborhood-Level Risks for Childhood Obesity in ELA. Journal of Adolescent Health, 40, 325-333.

[14] Bronfenbrenner, U. (1979) The Ecology of Human Development: Experiments by Nature and Design. Harvard University Press, Cambridge.

[15] Ruelas, V., Iverson, E., Kiekel, P. and Peters, A. (2012) The Role of Farmers' Markets in Two Low Income, Urban Communities. Journal of Community Health, 37, 554-562. http://dx.doi.org/10.1007/s10900-011-9479-y 
Scientific Research Publishing (SCIRP) is one of the largest Open Access journal publishers. It is currently publishing more than 200 open access, online, peer-reviewed journals covering a wide range of academic disciplines. SCIRP serves the worldwide academic communities and contributes to the progress and application of science with its publication.

Other selected journals from SCIRP are listed as below. Submit your manuscript to us via either submit@scirp.org or Online Submission Portal.
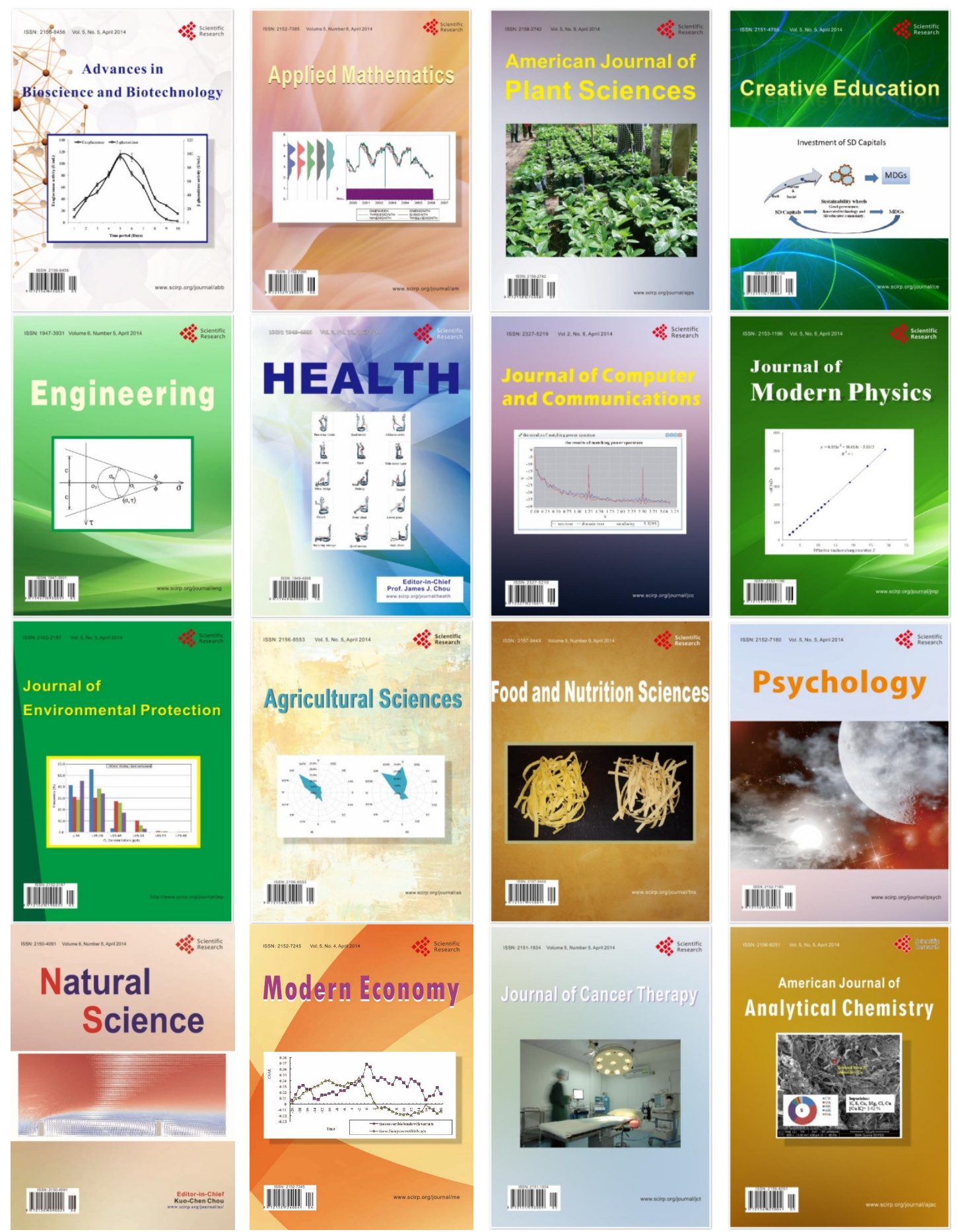